\title{
Results of total correction of the tetralogy of Fallot Long-term haemodynamic evaluation at rest and during exercise
}

\author{
P. Finnegan ${ }^{1}$, R. Haider ${ }^{2}$, R. G. Patel ${ }^{3}$, L. D. Abrams, and S. P. Singh \\ From the Department of Medicine, University of Birmingham, Queen Elizabeth Hospital, and Birmingham \\ Children's Hospital
}

Postoperative haemodynamic evaluation was performed on 15 patients 7 to 14 years (mean, 11 years) after total intracardiac repair of Fallot's tetralogy. The average age of the patients at the time of postoperative catheterization was 20 years (range 12 to 29) and they were all asymptomatic. Before operation 11 patients were severely cyanosed and disabled and 4 had mild cyanosis with anoxic spells.

The cardiac output and right heart pressures were measured at rest and after 5 minutes of submaximal exercise on a bicycle ergometer. It was shown that the degree of residual obstruction of the pulmonary outflow tract was slight and that the right ventricular/pulmonary arterial systolic gradient (RV|PA gradient) exceeded $20 \mathrm{mmHg}(2.6 \mathrm{kPa})$ at rest in only 3 patients. The mean cardiac index at rest was $5.41 \mathrm{~min}^{-1} \mathrm{~m}^{-2}$ which increased to $8.3 \mathrm{l} \mathrm{min}-1 \mathrm{~m}^{-2}$ during exercise. The response of the cardiac output during exercise was either normal or supranormal in 14 of the 15 patients. In the remaining patient the response was marginally below the normal range.

Pulmonary valvular regurgitation was present in 8 patients but there was no detectable difference in the cardiac function of these patients compared with patients with competent pulmonary valves.

Six of the patients investigated had also had cardiac catheterizations performed 1 to 4 years after operation. The results of the present study show that remarkably little change has occurred in their haemodynamic status in the intervening years. Though these results are encouraging, further studies are required to determine the eventual outcome of the $R V$ pressure and volume overload.

Total intracardiac correction of the tetralogy of Fallot is now well established as a highly successful surgical procedure (Kirklin and Karp, 1970). The symptomatic and clinical improvement which occurs after operation is usually dramatic. It is not surprising, however, that residual haemodynamic abnormalities have been shown by postoperative

Received 27 February 1976.

${ }^{1}$ Present address: Regional Hospital, Galway, Republic of Ireland.

2Present address: Division of Cardiology, Department of Medicine, The George Washington University Medical Center, 2150 Pennsylvania Avenue, N.W., Washington D.C. 20037.

${ }^{3}$ Present address: The Hospital for Sick Children, Great Ormond Street, London WC1. catheterization studies (Hallidie-Smith et al., 1967; Soulié et al., 1971; Sunderland et al., 1973; Kaplan et al., 1973; Gersony et al., 1973).

Two main abnormalities have been described:

(1) Residual obstruction of the right ventricular outflow tract which is usually mild or moderate in degree.

(2) Pulmonary valvular regurgitation, particularly when a prosthetic or pericardial patch is used to enlarge the right ventricular outflow tract and the pulmonary artery.

In a minority of patients the persistence of a shunt through a ventricular septal defect has been shown.

Many of the postoperative studies were done relatively soon after total correction and there is an 
obvious need to determine the long-term effects of the residual haemodynamic defects. In addition, the majority of follow-up catheterizations did not examine the effects of exercise on the right ventricular outflow tract gradient and the cardiac output. The haemodynamic response to submaximal exercise in the supine position has been reported (Malm et al., 1966; Gotsman, 1966; Bristow et al., 1970; Joransen and Moller, 1972; Shah and Kidd, 1966) and intense exercise in the upright position has been the subject of one report (Epstein et al., 1973).

The present studies were undertaken to evaluate the long-term haemodynamic results at rest and during exercise in 15 patients approximately 11 years after total correction. It was also possible to make an assessment of the serial haemodynamic changes in 6 patients who had been studied 1 to 4 years after operation (Gotsman, 1966).

\section{Patients and methods}

Fifteen patients, 8 male and 7 female, were investigated 7 to 14 years after total correction of Fallot's tetralogy, and in 11 patients the interval was greater than 10 years. Their average age at the time of investigation was 20 years (range 12 to 29 years) and they were all asymptomatic and leading normal lives. They were selected because they were the earliest survivors of the total correction operation in our unit. The purpose and nature of the investigation was fully explained to each patient or patients as appropriate and informed consent for its performance obtained.

Before operation 11 patients were severely cyanosed and 4 had mild cyanosis with anoxic spells. The diagnosis was based on the clinical signs, haemodynamic and angiographic investigation, and the findings were confirmed at operation.

\section{Operation details}

Five patients had preliminary palliative operations, viz. a pulmonary valvotomy in 3 and a Blalock anastomosis in 2. At the time of total correction pulmonary infundibulectomy was done in all 15 patients and in addition 8 patients had a pulmonary valvotomy. The ventricular septal defect was repaired with a 'teflon' patch in 9 patients and in the other 6 patients the defect was closed by direct suture. The right ventricular outflow tract was widened with a 'teflon' prosthetic patch in 7 patients and in 2 of these the prosthetic patch was extended to widen the proximal pulmonary artery.

\section{Procedure for cardiac catheterization}

Right heart catheterization was performed in the supine position and in the fasting state without earlier sedation. A No. 9 double-lumen Cournand catheter was used in most studies and the intracardiac pressures were measured by Sanborn transducers (Model 267 BC) and recorded on an ultraviolet photographic recorder. The pulmonary arterial and right ventricular pressures were determined by planimetry over several respiratory cycles. The right ventricular end-diastolic pressure (RVEDP) was measured after the ' $a$ ' wave. The zero reference level for pressure was $10 \mathrm{~cm}$ above the plane of the catheterization table. The oxygen saturation of blood samples from the superior vena cava, inferior vena cava, right atrium, right ventricle, pulmonary artery, and brachial artery was determined by a spectrophotometric method. The cardiac output was measured by the direct Fick method. The expired air was collected in a Tissot spirometer while samples of blood were withdrawn from the pulmonary artery and brachial artery

TABLE 1 Postoperative data in 15 patients with tetralogy of Fallo:

\begin{tabular}{|c|c|c|c|c|}
\hline & $\begin{array}{l}\text { Rest } \\
\text { Mean }\end{array}$ & Range & $\begin{array}{l}\text { Exercise } \\
\text { Mean }\end{array}$ & Range \\
\hline Mean RAP (mmHg) & 5 & $-1-10$ & 7 & $1-10$ \\
\hline RVSP (mmHg) & 39 & $22-61$ & 54 & $23-83$ \\
\hline RVEDP (mmHg) & 6 & $0-13$ & 7 & $-2-12$ \\
\hline PASP $(\mathrm{mmHg})$ & 24 & $14-36$ & 33 & $18-49$ \\
\hline PADP (mmHg) & 8 & $-1-18$ & 13 & $5-22$ \\
\hline Mean PAP (mmHg) & 15 & $6-26$ & 22 & $8-33$ \\
\hline RV/PA systolic pressure & & & & \\
\hline gradient $(\mathrm{mmHg})$ & 15 & $1-46$ & 23 & $3-59$ \\
\hline PAWP (mmHg) & 8 & $0-19$ & 13 & $4-30$ \\
\hline BA systolic (mmHg) & 128 & 99-150 & 160 & $120-181$ \\
\hline BA diastolic ( $\mathrm{mmHg}$ ) & 84 & $67-102$ & 101 & $72-119$ \\
\hline PVR (dynes's. $\mathrm{cm}^{-5}$ ) & 87 & $36-175$ & 65 & $11-141$ \\
\hline Systemic resistance & & & & \\
\hline (dynes $\cdot \mathrm{s} \cdot \mathrm{cm}^{-5}$ ) & 1080 & $508-1724$ & 956 & 487-899 \\
\hline $\begin{array}{l}\text { Systemic arterial oxygen } \\
\text { saturation (\%) }\end{array}$ & 95 & 88-99 & 95 & $86-98$ \\
\hline $\begin{array}{l}\text { AV oxygen difference } \\
(\text { vol } \%)\end{array}$ & $3 \cdot 3$ & $2 \cdot 1-4 \cdot 8$ & $8 \cdot 0$ & $5 \cdot 4-11 \cdot 3$ \\
\hline $\begin{array}{l}\text { Cardiac index } \\
\left(1 \mathrm{~min}^{-1} \mathrm{~m}^{-2}\right)\end{array}$ & $5 \cdot 4$ & $3 \cdot 2-8 \cdot 5$ & $8 \cdot 3$ & $5 \cdot 1-11 \cdot 8$ \\
\hline Heart rate (beats/min) & 88 & $72-108$ & 135 & $108-166$ \\
\hline Stroke volume (ml/beat) & 96 & $62-185$ & 100 & $61-173$ \\
\hline $\begin{array}{l}\text { Oxygen consumption } \\
\left(\mathrm{ml} \mathrm{min}^{-1} \mathrm{~m}^{-2}\right)\end{array}$ & 153 & $113-192$ & 597 & $444-755$ \\
\hline
\end{tabular}

Abbreviations: RAP, right atrial pressure; RVSP, right ventricular systolic pressure; RVEDP, right ventricular enddiastolic pressure; PASP, pulmonary artery systolic pressure; PADP, pulmonary artery diastolic pressure; PAP, pulmonary artery pressure; PAWP, pulmonary artery wedge pressure; BA, brachial artery; PVR, pulmonary vascular resistance; AV, arteriovenous.

Conversion factors from Traditional Units to SI Units; $1 \mathrm{mmHg} \approx 0 \cdot 133 \mathrm{kPa} ; 10$ dynes $\cdot \mathrm{s} \cdot \mathrm{cm}^{-5}=1 \mathrm{MPa} \cdot \mathrm{s} \cdot \mathrm{m}^{-3}$. 
simultaneously. The gas samples were analysed for oxygen content by the Scholander micro-method. The cardiac output was measured at rest and during the fifth minute of exercise on a bicycle ergometer. The degree of workload selected for each patient was approximately two-thirds of the predetermined maximum load and it was maintained for 5 minutes. Simultaneous pulmonary arterial (PA) and right ventricular (RV) pressures were recorded at the beginning and at the end of the gas collection.

\section{Electrocardiography}

All the patients had complete right bundle-branch block on their electrocardiograms but there was no evidence of left anterior hemiblock or complete atrioventricular dissociation.

\section{Results}

The physical characteristics of the patients and haemodynamic results at rest and during exercise are shown in Tables 1 and 2.

\section{Right heart pressures}

The mean values for the RV systolic pressure and the RV-PA systolic pressure gradient at rest and during exercise are given in Table 1 and the individual values are shown in Fig. 1 and 2 . The RV-PA systolic gradient at rest was $20 \mathrm{mmHg}$ $(2.7 \mathrm{kPa})$ or less in 12 of the 15 patients. An increase in the gradient during exercise was recorded in 14 patients but the increase was $<10 \mathrm{mmHg}(1.3 \mathrm{kPa})$ in 7 patients. The RV-LV peak pressure ratio

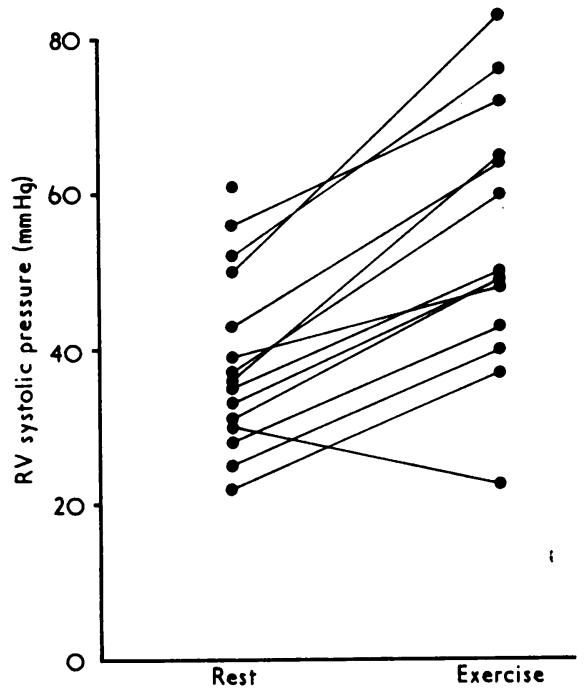

FIG. 1 Right ventricular systolic pressures at rest and during exercise.

averaged 0.31 (range 0.16 to 0.42 ) and there was no significant difference between the patients who had a patch repair of the RV outflow tract and those who did not.

The RVEDP was slightly increased ( $>5 \mathrm{mmHg}$; $0.7 \mathrm{kPa}$ ) in 10 patients at rest (Fig. 3). During exercise the RVEDP increased in 10 patients but the increase exceeded $5 \mathrm{mmHg}(0.7 \mathrm{kPa})$ in only 1 patient.

The mean pulmonary artery pressure (PAP) and pulmonary wedge pressures (PAWP) were within

TABLE 2 Physical characteristics and values for cardiac output, cardiac index, $\mathrm{AV} \mathrm{O}_{2}$ difference, and oxygen consumption at rest and during exercise

\begin{tabular}{|c|c|c|c|c|c|c|c|c|c|c|c|}
\hline \multirow[t]{2}{*}{$\begin{array}{l}\text { Case } \\
\text { No. }\end{array}$} & \multirow[t]{2}{*}{ Age } & \multirow[t]{2}{*}{ Sex } & \multirow[t]{2}{*}{$\begin{array}{l}B S A \\
\left(m^{2}\right)\end{array}$} & \multicolumn{2}{|c|}{$\begin{array}{l}A V \mathrm{O}_{2} \\
\text { Differences (vol \%) }\end{array}$} & \multicolumn{2}{|c|}{$\begin{array}{l}\text { Cardiac output } \\
\text { (l/min) }\end{array}$} & \multicolumn{2}{|c|}{$\begin{array}{l}\text { Cardiac index } \\
\left(l \min ^{-1} m^{-2}\right)\end{array}$} & \multicolumn{2}{|c|}{$\begin{array}{l}\text { Oxygen consumption index } \\
\left(\mathrm{ml} \mathrm{min}^{-1} \mathrm{~m}^{-2}\right)\end{array}$} \\
\hline & & & & Rest & Exercise & Rest & Exercise & Rest & Exercise & Rest & Exercise \\
\hline 1 & 21 & $\mathbf{M}$ & 1.69 & 3.8 & 8.9 & 6.4 & $13 \cdot 6$ & 3.8 & 8.0 & 143 & 714 \\
\hline 2 & 24 & $\mathrm{~F}$ & 1.49 & $2 \cdot 3$ & $6 \cdot 7$ & $10 \cdot 6$ & 9.9 & $7 \cdot 1$ & $6 \cdot 6$ & 166 & 444 \\
\hline 3 & 23 & $\mathrm{M}$ & 1.94 & $4 \cdot 0$ & $10 \cdot 7$ & $7 \cdot 3$ & $13 \cdot 3$ & 3.7 & 6.9 & 148 & 731 \\
\hline 4 & 23 & $\mathbf{F}$ & 1.59 & $2 \cdot 7$ & $5 \cdot 0$ & 6.7 & $15 \cdot 0$ & $4 \cdot 2$ & $9 \cdot 3$ & 113 & 465 \\
\hline 5 & 12 & $\mathbf{F}$ & $1 \cdot 44$ & $2 \cdot 3$ & $5 \cdot 7$ & $9 \cdot 7$ & $12 \cdot 7$ & $6 \cdot 8$ & $8 \cdot 8$ & 155 & 500 \\
\hline 6 & 17 & $\mathbf{M}$ & 1.63 & $2 \cdot 3$ & $6 \cdot 2$ & $13 \cdot 4$ & $15 \cdot 3$ & $8 \cdot 5$ & $9 \cdot 4$ & 192 & 585 \\
\hline 7 & 17 & $\mathbf{M}$ & 1.72 & 3.9 & $6 \cdot 8$ & 6.9 & $14 \cdot 0$ & 4.0 & $8 \cdot 2$ & 158 & 552 \\
\hline 8 & 19 & $\mathbf{M}$ & 1.81 & 3.8 & 10.9 & 6.5 & $11 \cdot 7$ & 3.6 & $6 \cdot \overline{5}$ & 138 & 703 \\
\hline 9 & 14 & $\mathbf{M}$ & 1.30 & 3.8 & 6.4 & $5 \cdot 8$ & $15 \cdot 4$ & 4.5 & $11 \cdot 8$ & 172 & 755 \\
\hline 10 & 29 & $\mathbf{F}$ & 1.64 & $2 \cdot 4$ & 6.5 & $10 \cdot 6$ & $14 \cdot 2$ & $6 \cdot 4$ & $8 \cdot 6$ & 153 & 561 \\
\hline 11 & 18 & $\mathbf{F}$ & 1.54 & 3.2 & 8.5 & 6.5 & $10 \cdot 0$ & $4 \cdot 3$ & 6.5 & 137 & 557 \\
\hline 12 & 17 & $\mathbf{F}$ & $1 \cdot 71$ & $2 \cdot 6$ & $7 \cdot 1$ & $10 \cdot 6$ & $15 \cdot 1$ & $6 \cdot 2$ & $8 \cdot 8$ & 163 & 621 \\
\hline 13 & 24 & $\mathbf{M}$ & 1.60 & $4 \cdot 8$ & $11 \cdot 3$ & 5.5 & $8 \cdot 2$ & $3 \cdot 4$ & $5 \cdot 1$ & 164 & 579 \\
\hline 14 & 17 & $\mathbf{M}$ & 1.78 & $2 \cdot 1$ & $5 \cdot 4$ & 15.0 & $18 \cdot 7$ & $8 \cdot 4$ & $10 \cdot 5$ & 180 & 566 \\
\hline 15 & 25 & F & 1.63 & $3 \cdot 6$ & $10 \cdot 0$ & $5 \cdot 2$ & $10 \cdot 2$ & $3 \cdot 2$ & $6 \cdot 3$ & 116 & 625 \\
\hline
\end{tabular}

Normal values at rest: (1) AV oxygen difference, 2.4 to 5.7 vol. $\%$; (2) cardiac index, 2.6 to $5.81 \mathrm{~min}^{-1} \mathrm{~m}^{-2}$; (3) oxygen consumption index, 110 to $192 \mathrm{ml} \mathrm{min}^{-1} \mathrm{~m}^{-2}$. Fuller details are given in a paper by Segeal et al. (1964). 


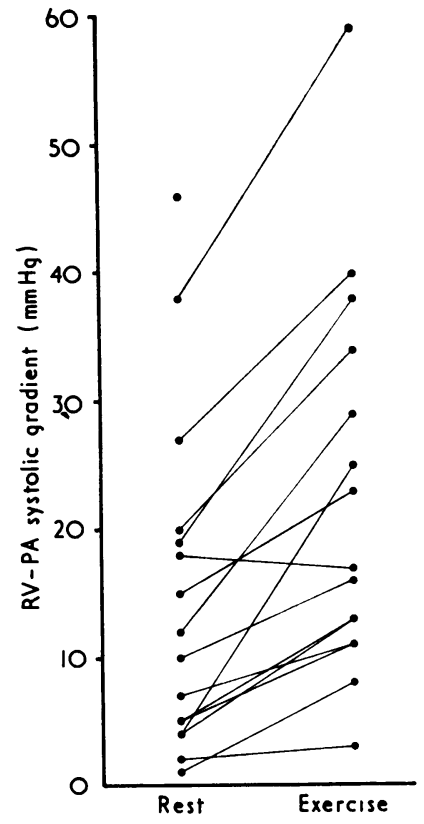

FIG. 2 Right ventricular-pulmonary arterial systolic pressure gradient at rest and during exercise.

normal limits at rest in all except one patient in whom the PAWP was $19 \mathrm{mmHg}(2.5 \mathrm{kPa})$. The mean pulmonary vascular resistance was also normal at rest and it decreased during exercise.

\section{Cardiac index (Table 2)}

The mean cardiac index at rest was $5.4 \pm 1.91 \mathrm{~min}^{-1}$ $\mathrm{m}^{-2}$ and was above the normal range for this laboratory $\left(2.6\right.$ to $\left.5.81 \mathrm{~min}^{-1} \mathrm{~m}^{-2}\right)$ in 6 patients. The relation between cardiac index and oxygen uptake during exercise was below normal in only 1 patient (Fig. 4).

At rest the mean $\mathrm{AV}$ oxygen difference and oxygen uptake were within the normal range. During exercise the mean oxygen uptake increased almost fourfold and the mean AV oxygen difference more than doubled. The values for 6 subjects were less than those for normal subjects doing a comparable level of exercise (Donald et al., 1955). The relation between the AV oxygen difference and the oxygen uptake for individuals is shown in Fig. 5.

\section{Stroke volume}

The stroke volume increased in 8 patients during exercise and decreased in 7 ; the changes were generally small (Fig. 6).

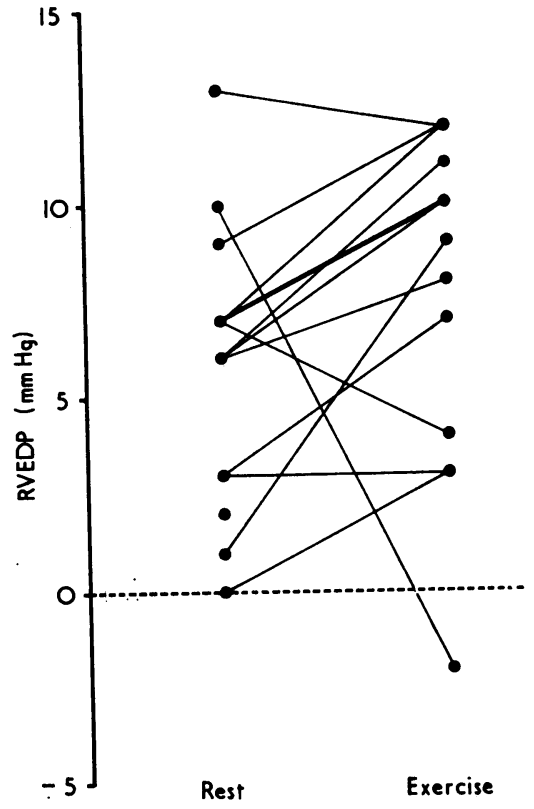

FIG. 3 Right ventricular end-diastolic pressures at rest and during exercise.

\section{Relation between stroke index and RVEDP during exercise (Fig. 7)}

The stroke index increased during exercise in 7 patients and this increase was accompanied by a rise in RVEDP in 5 patients. However, the increase in RVEDP did not exceed $5 \mathrm{mmHg}(0.7 \mathrm{kPa})$. A

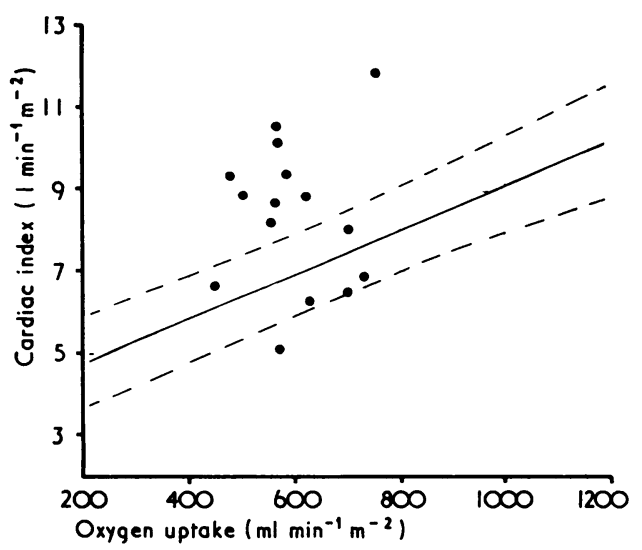

FIG. 4 Relation between cardiac index and oxygen uptake during exercise. The normal regression line and 95 per cent confidence limits are shown (Donalp et al., 1955). 
substantial fall in stroke index was observed in 2 patients and in 1 of these the RVEDP remained unchanged while in the other the RVEDP increased by $4 \mathrm{mmHg}(0.5 \mathrm{kPa})$. In one further patient the stroke index fell by $8 \mathrm{ml} \mathrm{min}^{-1} \mathrm{~m}^{-2}$ while the RVEDP increased from $1 \mathrm{mmHg}(0.1 \mathrm{kPa})$ to $9 \mathrm{mmHg}(1.2 \mathrm{kPa})$.

\section{Oxygen saturations}

The mean arterial oxygen saturation at rest and during exercise was identical ( $95 \pm 3$ per cent). Two patients showed a significant reduction of the arterial saturation at rest (90 and $88 \%$ ). In one of these patients an increase occurred during exercise from 90 to 93 per cent but a further reduction to 86 per cent was observed in the other patient.

Analysis of the right heart blood samples by spectrophotometer revealed no evidence of a leftto-right shunt.

\section{Effects of pulmonary regurgitation}

Eight patients had early diastolic murmurs in the pulmonary area and these showed haemodynamic evidence of pulmonary regurgitation (pulmonary artery diastolic pressure within 0 to $2 \mathrm{mmHg}$ ( 0 to $0.3 \mathrm{kPa}$ ) of the RVEDP).

In patients without pulmonary regurgitation the mean RVEDP at rest was $6 \mathrm{mmHg}(0.8 \mathrm{kPa})$ and it was unchanged during exercise. The mean RVEDP at rest was also $6 \mathrm{mmHg}(0.8 \mathrm{kPa})$ in the patients with pulmonary regurgitation and exercise caused a slight increase to $9 \mathrm{mmHg}(1.2 \mathrm{kPa})$. The

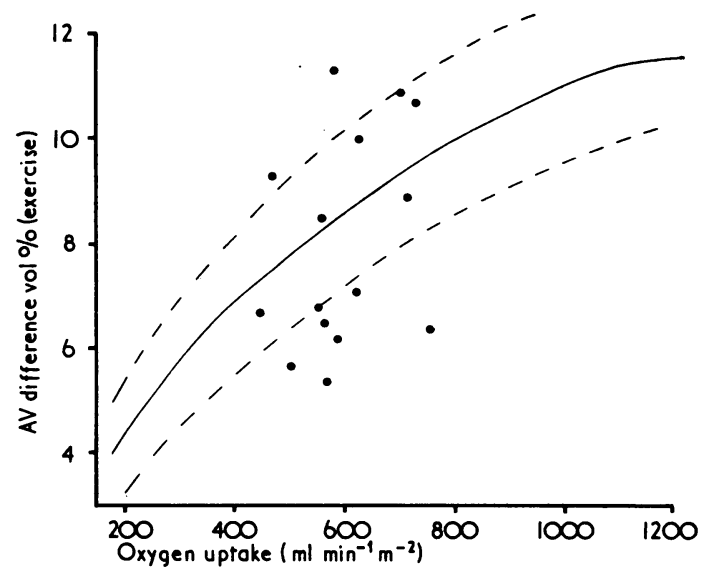

FIG. 5 Relation between $A V$ oxygen difference and oxygen uptake during exercise. The normal regression line and 95 per cent confidence limits are shown (Donald et al., 1955). highest individual value recorded at rest was $13 \mathrm{mmHg}(1.7 \mathrm{kPa})$ in a patient with pulmonary regurgitation (Fig. 3).

The mean pulmonary artery pulse pressure was $19 \pm 6 \mathrm{mmHg}(2.5 \pm 0.8 \mathrm{kPa})$ in the patients with pulmonary regurgitation compared to $13 \pm 5 \mathrm{mmHg}$ $(1.7 \pm 0.7 \mathrm{kPa})$ in those without pulmonary regurgi-

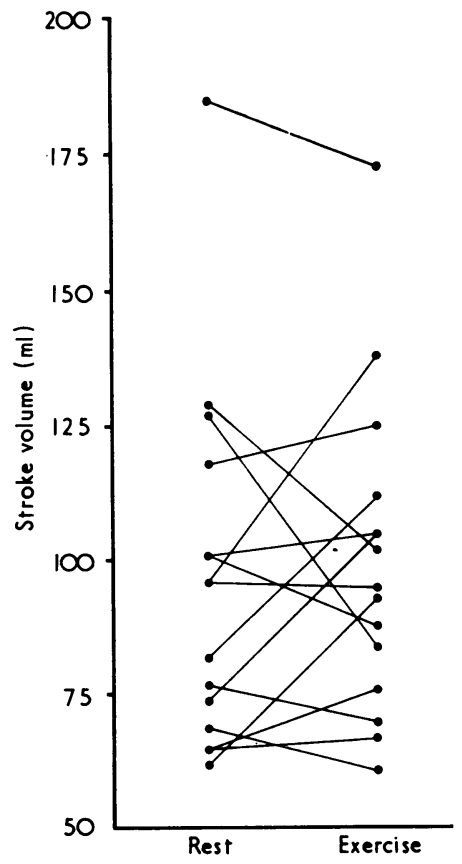

FIG. 6 The stroke volume for individual patients at rest and the changes occurring during exercise.

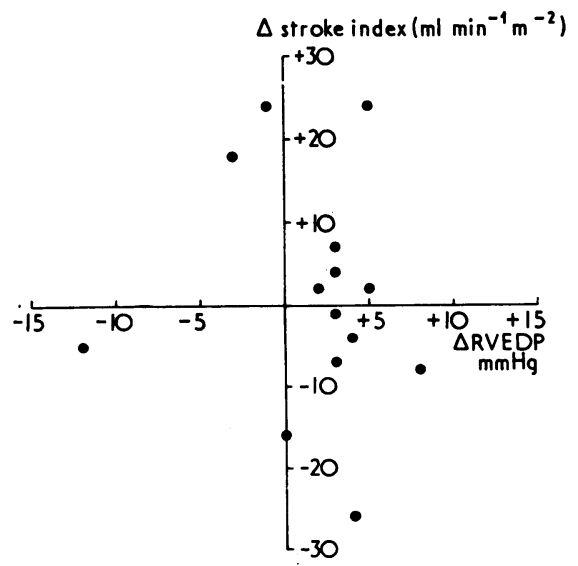

FI G. 7 Changes in stroke index and right ventricular end-diastolic pressure during exercise. 
TABLE 3 Comparison of early and late haemodynamic results at rest in 6 patients

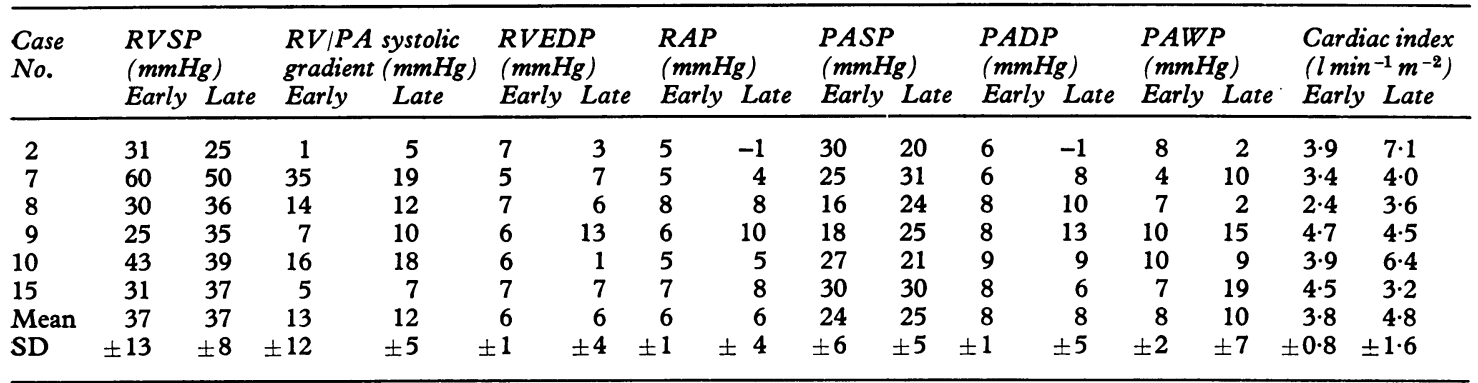

Abbreviations: as for Table 1.

tation; this difference is not statistically significant $(P>0.05)$. Minor differences in the cardiac output were observed in the two groups at rest and on exercise. The mean cardiac index at rest in patients with pulmonary regurgitation was $6.11 \mathrm{~min}^{-1} \mathrm{~m}^{-2}$ increasing to $9.01 \mathrm{~min}^{-1} \mathrm{~m}^{-2}$ on exercise compared to $4.61 \mathrm{~min}^{-1} \mathrm{~m}^{-2}$ increasing to $7.61 \mathrm{~min}^{-1} \mathrm{~m}^{-2}$. These differences were not statistically significant ( $P>0.1$ rest; $P>0.05$ exercise).

\section{Comparison of serial haemodynamic results}

The results of the early and late postoperative catheterization studies are compared in Table 3 and they show remarkably little change in the intervening years. The mean RV systolic pressure, RVEDP, RAP, and PA diastolic pressures are identical and there are only minor changes in the RV-PA gradient, PA systolic, PA mean, and PAWP. However, one patient showed a significant increase in the PAWP from 7 to $19 \mathrm{mmHg}(0.9$ to $2.5 \mathrm{kPa})$ at rest and from 14 to $30 \mathrm{mmHg}(1.9$ to $4.0 \mathrm{kPa}$ ) during exercise. The effects of exercise were measured in only 3 patients who showed no significant haemodynamic change between the two studies.

The mean cardiac index in the early study was $3.8 \pm 0.81 \mathrm{~min}^{-1} \mathrm{~m}^{-2}$ compared to $4.8 \pm 1.61 \mathrm{~min}^{-1}$ $\mathrm{m}^{-2}$ in the later study. The difference is not statistically significant $(P>0 \cdot 1)$. The mean AV oxygen difference at rest in both studies was within the normal range and only 1 patient had a value significantly greater than normal during exercise.

\section{Discussion}

The majority of haemodynamic studies after total correction for Fallot's tetralogy have shown a decrease in the RV/PA systolic pressure gradient in later studies compared with measurements made immediately after operation (Kirklin and Karp, 1970; Muraoka et al., 1973). The results of cathe- terizations performed 5 to 6 years postoperatively compared with 1 year after operation have shown little subsequent haemodynamic change (Gotsman et al., 1969; Bristow et al., 1970). The RV/LV ratio was selected by Hawe et al. (1972) as the most valid indicator of the degree of pulmonary stenosis. They studied 37 patients and showed in 25 patients that the $\mathrm{RV} / \mathrm{LV}$ ratio decreased between the completion of repair and restudy by 10 to 53 per cent. The ratio was unchanged in 4 patients and in 8 it was increased by 10 to 73 per cent.

In our study the $\mathrm{RV} / \mathrm{LV}$ peak pressure ratio was 0.31 (range 0.16 to 0.42 ) and this indicates satisfactory relief of the pulmonary stenosis. It was also noted that the ratio did not differ significantly between patients who had a prosthetic patch in the right ventricular outflow tract and those who did not. Exercise caused an increase in the $\mathrm{RV} / \mathrm{PA}$ systolic pressure gradient but the increase was slight or trivial in the majority of patients though more intense exercise would probably have shown a further increase (Epstein et al., 1973). Nevertheless, the increase in pulmonary blood flow during exercise was well tolerated. Another important observation was the unchanged RV/PA systolic pressure gradient in the patients catheterized previously. The relatively small increase in the $\mathrm{RV} / \mathrm{PA}$ gradient during exercise and the constancy of the haemodynamic measurements with the passage of time strongly suggests that the restoration of a normal pulmonary blood flow provides an adequate stimulus for the growth of the right ventricular outflow tract and the pulmonary arteries.

\section{Right ventricular myocardial function}

The RVEDP was greater than $5 \mathrm{mmHg}(0.7 \mathrm{kPa})$ in 10 patients and instead of the normal fall during exercise the RVEDP showed a further slight increase. Pulmonary regurgitation is one possible reason for the increased RVEDP but diminished 
right ventricular compliance caused by persisting muscular hypertrophy or myocardial fibrosis may also be important. A fall in the stroke volume index and a concomitant increase in the RVEDP during exercise has been interpreted as indicating abnormal right ventricular myocardial function in patients with Fallot's tetralogy after total correction (Joransen and Moller, 1972) and also after pulmonary valvotomy for pulmonary stenosis (Finnegan et al., 1974; Stone et al., 1974). A similar occurrence was observed in 5 patients in the present study. Because of the presence of pulmonary regurgitation and the brevity of the isovolumic period in the right ventricle, it was not possible to derive indices of myocardial contractility (Vmax, Vpm) and therefore a more direct assessment of myocardial contractile function was not made.

\section{Pulmonary hypertension}

An increase in the pulmonary vascular resistance has been observed in the early postoperative period in the majority of patients (Albertal, Swan, and Kirklin, 1964) and in some patients thereafter (Lillehei et al., 1964; Hallidie-Smith et al., 1967; Gersony et al., 1973; Kinsley et al., 1974). However, other studies have shown a normal pulmonary vascular resistance and mean pulmonary artery pressures (Gotsman, 1966; Bristow et al., 1970; Epstein et al., 1973; Shah and Kidd, 1966). In our study there was no evidence of pulmonary arterial hypertension at rest or during exercise. The fall in the pulmonary vascular resistance during exercise shows the ability of the pulmonary vascular system to accommodate the increased pulmonary blood flow. This finding lends support to the view that the thrombotic lesions, seen in the pulmonary arteries of cyanotic patients, usually resolve when the pulmonary blood flow increases (Ferencz, 1960).

\section{Pulmonary valvular regurgitation}

The problem of pulmonary valvular regurgitation after total correction continues to cause concern as to its ultimate effects on right ventricular function. Though some authors consider pulmonary regurgitation to be the major postoperative problem (Soulié et al., 1971), others have concluded that it appears to be well tolerated (Malm et al., 1963; Gotsman, 1966; Jones et al., 1973; Sunderland et al., 1973).

In our study there was no significant difference in the resting cardiac output or the response to exercise in patients with and without pulmonary regurgitation. The slight increase in RVEDP during exercise was the main difference between the two groups. It appears, therefore, that pulmonary regurgitation is well tolerated but further observation is necessary to determine its ultimate significance because a long-term experimental study of pulmonary regurgitation has shown the development of right ventricular dilatation and hypertrophy and a reduced resting cardiac output (Ellison et al., 1970).

\section{Recurrence of ventricular septal defect}

Several authors report that the ventricular septal defect reopens in a small number of patients after total correction (Bristow et al., 1970; Sunderland et al., 1973; Joransen and Moller, 1972). Analysis of the right heart blood samples by spectrophotometer showed no evidence of left-to-right shunting in any of our patients. This does not exclude the presence of a small left-to-right shunt but more sensitive methods of shunt detection were not used by us.

\section{Systemic oxygen saturations}

The arterial oxygen saturations were normal in all except 2 patients at rest. One patient had an oxygen saturation of 90 per cent which increased to 93 per cent during exercise. The other patient had an oxygen saturation of 88 per cent and a further decrease to 86 per cent occurred during exercise. This patient was asymptomatic and had a high resting cardiac output, a normal response of the cardiac output during exercise, and a trivial degree of right ventricular outflow tract obstruction (RV/PA systolic gradient at rest $=5 \mathrm{mmHg}(0.7 \mathrm{kPa}))$. The reason for the arterial unsaturation is, therefore, unexplained but it may be attributable to a persistent abnormality of pulmonary blood flow distribution.

\section{Left ventricular function}

Abnormal left ventricular function has been reported before and after total correction of Fallot's tetralogy (Jarmakani et al., 1972). The main abnormality described was a decreased left ventricular ejection fraction. Left ventricular function was not studied directly by us but the pulmonary wedge pressure was within normal limits in 14 patients. One patient had a PAWP at rest of $19 \mathrm{mmHg}$ $(2.5 \mathrm{kPa})$ which increased to $30 \mathrm{mmHg}(4.0 \mathrm{kPa})$. during exercise. In the majority of patients, however, the failure to develop pulmonary hypertension and the response of the stroke volume during exercise probably indicates normality of $\mathrm{LV}$ function. 


\section{Cardiac output}

The mean resting cardiac index for the group was $5.41 \mathrm{~min}^{-1} \mathrm{~m}^{-2}$ which is at the upper limit of normal and 6 patients had cardiac outputs above the normal range. Six subjects had a normal response of the cardiac output during exercise and 1 patient was slightly below the normal range. The remaining 8 patients had high cardiac outputs during exercise and this was associated with low AV oxygen differences. Though the patients were generally anxious there was no evidence of hyperventilation during the catheterization procedure or any other reason for the high output state such as anaemia, thyrotoxicosis, or arteriovenous shunting. However, the presence of small left-to-right shunts undetected by analysis of oxygen saturations is a possible explanation.

In normal subjects the response of the stroke volume during exercise is variable; it usually increases or is unaltered but it may fall (Donald et al., 1955). In patients with pulmonary stenosis studied postoperatively, a similar variability was observed (Finnegan et al., 1974; Stone et al., 1974). Another study of patients with pulmonary stenosis showed that in the presence of mild stenosis the stroke volume increased on exercise but when the stenosis was more severe the stroke volume remained constant (Moller, Rao, and Lucas, 1972). In our study the changes in stroke volume during exercise were also variable. The stroke volume increased in 8 subjects and decreased in 7, though a substantial decrease was observed in only 2 patients $(38 \mathrm{ml}$ and $27 \mathrm{ml})$.

The response of the cardiac output during submaximal exercise testing is clearly very satisfactory, but testing during more intensive exercise has shown a consistently reduced response (Epstein et al., 1973). Nevertheless, considering the presence of residual defects such as right ventricular outflow tract obstruction and pulmonary regurgitation, the performance of these patients during exercise is remarkably good. The ultimate effect of the residual abnormalities can only be determined by further clinical and haemodynamic studies.

\section{References}

Albertal, G., Swan, H. J. C., and Kirklin, J. W. (1964). Hemodynamic studies two weeks to six years after repair of tetralogy of Fallot. Circulation, 29, 583.

Bristow, J. D., Kloster, F. E., Lees, M. H., Menashe, V. D., Griswold, H. E., and Starr, A. (1970). Serial cardiac catheterizations and exercise hemodynamics after correction of tetralogy of Fallot. Circulation, 41, 1057.

Donald, K. W., Bishop, J. M., Cumming, G., and Wade, O. L. (1955) The effect of exercise on the cardiac output and circulatory dynamics of normal subjects. Clinical Science, 14, 37.
Ellison, R. G., Brown, W. J., Yeh, T. J., and Hamilton, W. F. (1970). Surgical significance of acute and chronic pulmonary valvular insufficiency. Fournal of Thoracic and Cardiovascular Surgery, 60, 549.

Epstein, S. E., Beiser, G. D., Goldstein, R. E., Rosing, D. R., Redwood, D. R., and Morrow, A. G. (1973). Hemodynamic abnormalities in response to mild and intense upright exercise following operative correction of an atrial septal defect or tetralogy of Fallot. Circulation, 47, 1065.

Ferencz, C. (1960). The pulmonary vascular bed in tetralogy of Fallot. II. Changes following a systemic-pulmonary arterial anastomosis. Bulletin of the fohns Hopkins Hospital, 106, 100.

Finnegan, P., Ihenacho, H. N. C., Singh, S. P., and Abrams, L. D. (1974). Haemodynamic studies at rest and during exercise in pulmonary stenosis after surgery. British Heart Fournal, 36, 913.

Gersony, W. M., Batthany, S., Bowman, F. O., and Malm, J. R. (1973). Late follow-up of patients evaluated hemodynamically after total correction of tetralogy of Fallot. fournal of Thoracic and Cardiovascular Surgery, 66, 209.

Gotsman, M. S. (1966). Haemodynamic and cine-angiocardiographic findings after one-stage repair of Fallot's tetralogy. British Heart fournal, 28, 448.

Gotsman, M. S., Beck, W., Barnard, C. N., O'Donovan, T. G., and Schrire, V. (1969). Results of repair of tetralogy of Fallot. Circulation, 40, 803.

Hallidie-Smith, K. A., Dulake, M., Wong, M., Oakley, C. M., and Goodwin, J. F. (1967). Ventricular structure and function after radical correction of the tetralogy of Fallot. British Heart fournal, 29, 533.

Hawe, A., McGoon, D. C., Kincaid, O. W., and Ritter, D. G. (1972). Fate of outflow tract in tetralogy of Fallot. Annals of Thoracic Surgery, 13, 137.

Jarmakani, J. M. M., Graham, T. P., Canent, R. V., and Jewett, P. H. (1972). Left heart function in children with tetralogy of Fallot before and after palliative or corrective surgery. Circulation, 46, 478.

Jones, E. L., Conti, C. R., Neill, C. A., Gott, V. L., Brawley, R. K., and Haller, J. A. (1973). Long-term evaluation of tetralogy patients with pulmonary valvular insufficiency resulting from outflow-patch correction across the pulmonic annulus. Circulation, 48, Suppl. 3, 11.

Joransen, J. A., and Moller, J. H. (1972). Postoperative hemodynamic studies in tetralogy of Fallot. Circulation, 46, Suppl. 2, 98.

Kaplan, S., Helmsworth, J. A., McKinivan, C. E., Benzing, G., Schwartz, D. C., and Schreiber, J. T. (1973). The fate of reconstruction of the right ventricular outflow tract. fournal of Thoracic and Cardiovascular Surgery, 66, 361.

Kinsley, R. H., McGoon, D. C., Danielson, G. K., Wallace, R. B., and Mair, D. D. (1974). Pulmonary arterial hypertension after repair of tetralogy of Fallot. Fournal of Thoracic and Cardiovascular Surgery, 67, 110.

Kirklin, J. W., and Karp, R. B. (1970). The Tetralogy of Fallot from a Surgical Viewpoint. W. B. Saunders, Philadelphia.

Lillehei, C. W., Levy, M. J., Adams, P., and Anderson, R. C. (1964). Corrective surgery for tetralogy of Fallot. Longterm follow-up by postoperative recatheterization in 69 cases and certain surgical considerations. Fournal of Thoracic and Cardiovascular Surgery, 48, 556.

Malm, J. R., Blumenthal, S., Bowman, F. O., Ellis, K., Jameson, A. G., Jesse, M. J., and Yeoh, C. B. (1966). Factors that modify hemodynamic results in total correction of tetralogy of Fallot. Fournal of Thoracic and Cardiovascular Surgery, 52, 502.

Malm, J. R., Bowman, F. O., Jameson, A. G., Ellis, K., 
Griffiths, S. P., and Blumenthal, S. (1963). An evaluation of total correction of tetralogy of Fallot. Circulation, 27, 805.

Moller, J. H., Rao, S., and Lucas, R. V. (1972). Exercise hemodynamics of pulmonary valvular stenosis. Circulation, 46, 1018.

Muraoka, R., Yokota, M., Matsuda, K., Tabata, R., and Hikasa, Y. (1973). Long term hemodynamic evaluation of primary total correction of tetralogy of Fallot during the first two years of life. Archiv fur japanische Chirurgie, 42, 315.

Segeal, N., Hudson, W. A., Harris, P., and Bishop, J. M. (1964). The circulatory effects of electrically induced changes in ventricular rate at rest and during exercise in complete heart block. fournal of Clinical Investigation, 43, 1541.

Shah, P., and Kidd, L. (1966). Hemodynamic responses to exercise and to isoproterenol following total correction of
Fallot's tetralogy. Fournal of Thoracic and Cardiovascular Surgery, 52, 138.

Soulié, P., Fouchard, J., Bouchard, F., Tricot, J. L., Albou, E., Caramanian, M., and DeGeorges, M. (1971). Résultats de la réparation complète de la tétralogie de Fallot. Archives des Maladies du Coeur et des Vaisseaux, 64, 1751.

Stone, F. M., Bessinger, F. B., Lucas, R. V., and Moller, J. H. (1974). Pre- and postoperative rest and exercise hemodynamics in children with pulmonary stenosis. Circulation, 49, 1102.

Sunderland, C. O., Matarazzo, R. G., Lees, M. H., Menashe, V. D., Bonchek, L. I., Rosenberg, J. A., and Starr, A. (1973). Total correction of tetralogy of Fallot in infancy. Postoperative hemodynamic evaluation. Circulation, 48, 398.

Requests for reprints to Dr. P. Finnegan, Regional Hospital, Galway, Republic of Ireland. 